\title{
SULPHUR: COMPATIBILITY WITH A DMI FOR GRAPEVINE POWDERY MILDEW CONTROL
}

\author{
G. CHIVERS, A. DOMNEY, G. HARRIS and P. LOBB \\ Zelam Ltd., Hudson Rd, New Plymouth, New Zealand \\ Corresponding author: gchivers@zelam.com
}

The 2007 NZ Winegrowers Spray Schedule advises against mixing sulphur with DMI fungicides because "research from Europe has demonstrated there can be reduced activity of the DMIs when mixed with sulphur". When a literature search by Zelam Ltd failed to find any hard data to support this, a series of trials was initiated to determine if sulphur was indeed antagonistic to the efficacy of myclobutanil ( $125 \mathrm{~g} /$ litre as Prostar) on grapevine powdery mildew (Uncinula necator). Although only 2 of the 5 trials had high disease pressure, there were no data to support the hypothesis of antagonism between myclobutanil and sulphur. All trials showed equal efficacy between the myclobutanil and the myclobutanil+sulphur treatments for powdery mildew control in grapes. On the basis of this research, Zelam has altered the label for Prostar to state "Prostar can be mixed with sulphur". This gives growers the ability to tank mix sulphur (a protectant with a different mode of action) with every application of myclobutanil to minimise the risk of resistance. Furthermore, sulphur cover sprays, an important tool for grape erineum mite (Colomerus vitis) control, can be maintained unabated. 